\title{
Association Between Obesity and Depression Among American Blacks: Role of Ethnicity and Gender
}

\author{
Shervin Assari
}

Received: 20 October 2013 / Revised: 6 December 2013 / Accepted: 2 January 2014 /Published online: 24 January 2014

(C) Cobb/NMA Health Institute 2014

\begin{abstract}
Aim This study tested the association between obesity and major depressive disorder (MDD) in a national representative sample of Black adults in the USA. The study also explored the above association in subsamples based on ethnicity and gender.

Method Data came from the National Survey of American Life (NSAL), a household mental health survey of adult Black Americans. Participants consisted of 5,191 Black adults (3,570 African Americans and 1,621 Caribbean Blacks). Classes I to III of obesity were defined based on body mass index (BMI) of equal or larger than 30,35 , and $40 \mathrm{~kg} / \mathrm{m}^{2}$, respectively. Twelve-month MDD was determined using the World Mental Health Composite International Diagnostic Interview (CIDI), a fully structured diagnostic interview. For each ethnicitygender subgroup, we ran a separate logistic regression model. We tested gradient and threshold effects of BMI on MDD. Unadjusted and adjusted odds ratios (ORs) were reported.

Result Direction of association between BMI and MDD was reversed among men and women. Among men, there was a positive association between BMI and MDD, while among women, the association was negative. The gradient effect of BMI level on MDD reached statistical significance only among African American men (OR $=0.71,95 \%$ confidence interval $(\mathrm{CI})=0.51-0.99)$. Among women, a significant interaction was found between the effects of BMI $\geq 40$ and African American ethnicity on odds of developing MDD [change in $\mathrm{OR}=8.840,95 \% \mathrm{CI}=1.315-59.418$ ]
\end{abstract}

\section{S. Assari $(\bowtie)$}

Center for Research on Ethnicity, Culture, and Health (CRECH), Department of Health Behavior and Health Education, University of Michigan, School of Public Health, 1415 Washington Heights, Ann Arbor, MI 48109-2029, USA

e-mail: assari@umich.edu
That interaction term suggests that the effect of BMI $\geq 40$ on MDD is significantly smaller among African American women than Caribbean Black women.

Conclusion The direction and magnitude of the association between BMI and MDD among Blacks depend on ethnicity and gender. Risk of comorbid depression among women with severe obesity among Black women is smaller among African Americans than Caribbean Blacks.

Keywords African Americans · Blacks · Ethnicity · Gender · Obesity $\cdot$ Body Mass Index $\cdot$ Depression $\cdot$ Major Depressive Disorder

\section{Introduction}

Major depressive disorder (MDD) and obesity are two major public health problems, causing enormous public health burden [1-4]. Depression is the leading cause of disability [5], and obesity is a major cause of mortality [6].

Major depressive disorder is the most prevalent psychiatric disorder in the USA, affecting over $16 \%$ of adults [7]. Lifetime prevalence of MDD is $13 \%$ and $10 \%$ among Caribbean Blacks and African Americans, respectively [8]. Compared to Whites, MDD tends to be more severe and disabling and less frequently diagnosed and treated among Blacks [8]. With a consistent pattern across almost all US states, obesity is $50 \%$ more prevalent among Blacks than Whites [9].

Studies which have focused on the association between depression and obesity have provided mixed results [10]. As a result, researchers have shown interest in exploring the causes of the inconsistencies in the link between obesity and depression. This body of research has suggested a wide range of candidate moderators, including gender [11-15] and ethnicity [16]. 
Literature regarding the moderating effect of race and ethnicity has shown contradictory results [17, 18]. Gavin and colleagues analyzed the Comprehensive Psychiatric Epidemiology Surveys (CPES) data and reported that Blacks and Whites differ in the association between obesity and 12-month MDD. This study, however, did not test the possible moderating effect of ethnicity on the association between obesity and depression among Blacks. The study suggested that among women who are obese, prevalence of 12-month MDD is considerably lower among Blacks than Whites. They documented a significant interaction between the effect of race and obesity on MDD, suggesting that that the association between obesity and MDD is stronger among Whites than Blacks [17]. Another study by Sachs-Ericsson and coworkers, however, reported contrasting results by documenting a larger influence of body mass index (BMI) on depressive symptoms among African Americans than Whites [18].

Research has suggested that the association between obesity and MDD may be nonlinear [19]. Thus, the threshold effect may better explain the link between obesity and depression, compared to the simplistic linear (gradient) effect. However, findings regarding the threshold effect of obesity on MDD may depend on the setting of the study, as most clinical samples [20, 21], but not community studies [21], have suggested threshold effects.

The current study was conducted to test if African American and Caribbean Black men and women differ in the association between obesity and 12-month MDD. The study tested both gradient and threshold effects. As we used a representative sample of Black Americans, the results are believed to be generalizable to the population of Blacks in the USA.

\section{Methods}

This was a cross-sectional study, using data from the National Survey of American Life (NSAL), 2003. The NSAL is the largest mental health survey of a Black population ever conducted in the USA [22]. This study is a part of the Collaborative Psychiatric Epidemiology Surveys funded by the National Institute of Mental Health (NIMH). The study was approved by the Institute Review Board of the University of Michigan, Ann Arbor. All individuals provided written informed consent form, and data was collected anonymously. The consent form was mailed to the participants whose data was collected via telephone interview.

\section{Participants}

This study included all 5,191 Blacks who participated in NSAL-adults (total=6,082). The sample included 3,570 African Americans and 1,621 Caribbean Blacks. We did not include 881 White participants who were sampled in the NSAL. Participants were national household probability sample of individuals 18 years and older. All participants were residing in the USA at the time of study. Detailed report on the sampling has been reported elsewhere [23, 24]. Although African Americans were residents of either large cities or other urban and rural areas, Caribbean Blacks were only sampled from large cities.

African Americans were individuals who self-identified as Black but did not identify ancestral ties to the Caribbean. Caribbean Blacks are those who self-identified as Black and indicated that they were of West Indian or Caribbean descent, that they were from a country included on a list of Caribbean countries presented by the interviewers, or that their parents or grandparents were born in a Caribbean country.

The sample of Caribbean Blacks was from Englishspeaking Caribbean countries $(n=1,089)$, Haiti $(n=290)$, Spanish-speaking Caribbean ( $n=175)$, Dutch-speaking Caribbean $(n=7)$, or French-speaking countries other than Haiti $(n=4)$. All individuals were combined into one ethnic group, for comparability with the literature on with the respondents from the English-speaking Caribbean [25-29].

\section{Interview}

A computer-assisted personal interview (CAPI) was used for data collection among $86 \%$ of individuals. CAPI is an interviewing technique in which the respondent uses a computer to answer the questions. CAPI is a preferred method of interview when the questionnaire is long and complex. These interviews lasted an average of $140 \mathrm{~min}$. The remaining interviews were either partially or entirely conducted by telephone. All the interviews were performed in English. The final response rate was $72.3 \%$ overall: $70.7 \%$ for African Americans and $77.7 \%$ for Caribbean Blacks.

\section{Measures}

Twelve-month MDD was measured using the World Mental Health Composite International Diagnostic Interview (CIDI). CIDI is a fully structured diagnostic interview schedule, designed to evaluate a wide range of Diagnostic and Statistical Manual of Mental Disorder - IV (DSM-IV) mental disorders. This interview schedule is developed for the World Mental Health project initiated in 2000 [30]. The CIDI is developed for use by trained lay interviewers to generate diagnoses of lifetime and recent DSM-IV-TR/International Classification of Diseases (ICD-10) disorders [31]. Clinical reappraisal studies have documented generally good concordance of CIDI diagnoses with blinded clinical diagnoses [32, 33]. The CIDI uses extensive skip logic to reduce interview length [34]. Excellent concordance [based on area under the receiver operating characteristic curve (AUC)] has been found 
between CIDI-SC and DSM-IV/severe combined immunodeficiency (SCID) diagnoses of major depressive episodes (MDE) and generalized anxiety disorder (GAD). CIDI-SC versus SCID prevalence differences have been shown to be insignificant at the optimal CIDI-SC diagnostic thresholds. Individual-level diagnostic concordance at these thresholds is also substantial (AUC 0.81-0.86), with sensitivity of $68.0-80.2 \%$ and specificity of $90.1-98.8 \%$. As a result, CIDI-SC operating characteristics are equivalent for MDE and GAD to those of the best alternative screening scales [34]. This measure is believed to provide valid findings for Blacks and ethnic groups of Blacks [35-40].

The study registered sociodemographic correlates including age, gender, employment status, education years completed, household income (divided approximately into quartiles), marital status, country of birth, and country region.

Publicly available NSAL data has the variable of BMI level, which is calculated based on self-reported weights and heights. BMI based on self-reported weight and height is highly correlated with BMI based on direct measures of height and weight [16]. Some researchers, however, have argued that using self-reported weight and height may lead to underestimation of BMI [41], because of an underestimation of weight and overestimation of height [42]. Classes I to III of obesity were defined based on body mass index (BMI) of more than 30,35 , and $40 \mathrm{~kg} / \mathrm{m}^{2}$, respectively. Although the NSAL has originally collected weight in pounds $(1 \mathrm{lb}=0.453 \mathrm{~kg})$ and height in feet $(1 \mathrm{ft}=0.3048 \mathrm{~m})$ and inches $(1 \mathrm{in} .=0.0254 \mathrm{~m})$, a publicly available data set has calculated BMI levels.

\section{Statistical Analysis}

As the NSAL used a multistage sample design involving clustering and stratification, we used Stata 12.0 to account for the complex design. Any percentage represents weighted proportions based on the sample's race-adjusted weight measure; the standard errors reflect the recalculation of variance using the study's complex design. Logistic regression was used for multivariable analysis, by considering BMI level as the predictor and 12-month MDD as the main outcome. In different models, we tested the gradient and threshold effects of BMI, by considering it as a continuous and dichotomous variable, respectively. We conducted our analysis separately for each gender/ethnic group. An adjusted odds ratio (OR) and a $95 \%$ confidence interval $(\mathrm{CI})$ were reported. All analyses used the Taylor expansion approximation technique for calculating the complex design-based estimates of variance. While in the NSAL the Caribbean Black sample is more clustered than the African American sample, the corrected standard errors for these two groups are larger than those for the African American sample. Age, country region, education, income, marital status, and employment were controlled. $p$ values less than 0.05 were considered statistically significant.

\section{Results}

Most participants in both ethnic groups were between 30 and 44 years of age. Almost half of the participants in each ethnic group were women. African Americans and Caribbean Blacks were not significantly different in age, gender, and 12-month MDD. African Americans and Caribbean Blacks were different in being US born, living place, region of the country, and BMI level. Most Caribbean Blacks were born outside the USA, while only $3 \%$ of African Americans were born outside the USA. Although most African Americans lived in the South, the Northeast represented most Caribbean Blacks (Tables 1 and 2).

As Table 2 shows, the rates of 12-month MDD were $5.4 \%$ (95 \% CI=4.5-6.3) and $7.8 \%(95 \% \mathrm{CI}=3.8-11.7)$ among African Americans and Caribbean Blacks, respectively $(p>0.05)$. For African American and Caribbean Black women, these rates were $7.3 \%(95 \% \mathrm{CI}=6.1-8.4)$ and $5.2 \%(95 \% \mathrm{CI}=$ 2.8-7.7), respectively ( $p>0.05)$. Among African American and Caribbean Black men, $3.1 \%(95 \% \mathrm{CI}=2.1-4.1)$ and $10.2 \%$ (95\% CI $=2.2-18.2)$ had MDD during the previous year ( $p>0.05$ ). Six percent of African Americans $(95 \% \mathrm{CI}=5.1-7.0)$ and $3.2 \%$ of Caribbean Blacks $(95 \% \mathrm{CI}=1.3-5.1)$ were severely obese (class III of obesity; BMI $\geq 40$ ) (Tables 2, 3, and 4).

Table 1 Sociodemographic data among African Americans and Caribbean Blacks

\begin{tabular}{|c|c|c|c|c|}
\hline \multirow[t]{2}{*}{ Characteristics } & \multicolumn{2}{|c|}{$\begin{array}{l}\text { African Americans } \\
n=3,570\end{array}$} & \multicolumn{2}{|c|}{$\begin{array}{l}\text { Caribbean Blacks } \\
n=1,621\end{array}$} \\
\hline & Mean & $\mathrm{SE}$ & Mean & $\mathrm{SE}$ \\
\hline \multicolumn{5}{|l|}{ Age } \\
\hline & 42.3 & 0.5 & 40.9 & 0.9 \\
\hline & $n$ & $\%$ & $n$ & $\%$ \\
\hline \multicolumn{5}{|l|}{ Sex } \\
\hline Male & 1,271 & 36 & 643 & 40 \\
\hline Female & 2,299 & 64 & 978 & 60 \\
\hline \multicolumn{5}{|l|}{ Birth place* } \\
\hline Inside the USA & 3,464 & 97 & 440 & 27 \\
\hline Outside the USA & 64 & 2 & 1,166 & 72 \\
\hline \multicolumn{5}{|l|}{ Living place* } \\
\hline Large cities & 3,105 & 87 & 1,621 & 100 \\
\hline Other urban & 312 & 9 & 0 & 0 \\
\hline Rural area & 153 & 4 & 0 & 0 \\
\hline \multicolumn{5}{|l|}{ Region* } \\
\hline Northeast & 411 & 12 & 1,135 & 70 \\
\hline West & 234 & 7 & 18 & 1 \\
\hline Midwest & 595 & 17 & 12 & 1 \\
\hline South & 2,330 & 65 & 456 & 28 \\
\hline
\end{tabular}

$S E$ standard error

$* p<0.05$ 
Table 2 Distribution of major depressive disorder and body mass index (BMI) level among ethnic groups

\begin{tabular}{|c|c|c|c|c|c|c|c|c|}
\hline Characteristics & $\begin{array}{l}\% \\
\text { Africa }\end{array}$ & $\begin{array}{l}\mathrm{SE} \\
\text { Americ }\end{array}$ & Lower bound & Upper bound & $\begin{array}{l}\% \\
\text { Carib }\end{array}$ & $\begin{array}{l}\text { SE } \\
\text { in Black }\end{array}$ & Lower bound & Upper bound \\
\hline \multicolumn{9}{|l|}{ BMI level* } \\
\hline Underweight (BMI <18.5) & 1.7 & 0.003 & 1.1 & 2.3 & 1.5 & 0.004 & 0.7 & 02.3 \\
\hline Healthy weight (BMI 18.5-24.9) & 28.2 & 0.010 & 26.2 & 30.2 & 37.9 & 0.016 & 34.7 & 41.2 \\
\hline Overweight (BMI 25.0-29.9) & 34.7 & 0.009 & 32.9 & 36.6 & 35.9 & 0.018 & 32.1 & 39.7 \\
\hline Obesity class I (BMI 30.0-34.9) & 20.5 & 0.007 & 19.0 & 22.0 & 14.3 & 0.012 & 11.8 & 16.7 \\
\hline Obesity class II (35.0-39.9) & 8.9 & 0.005 & 7.8 & 10.0 & 7.3 & 0.010 & 5.2 & 9.3 \\
\hline Obesity class III (BMI >40) & 6.0 & 0.005 & 5.1 & 7.0 & 3.2 & 0.009 & 1.3 & 5.1 \\
\hline \multicolumn{9}{|l|}{ Depression in past year } \\
\hline No & 94.6 & 0.004 & 93.7 & 95.5 & 92.2 & 0.019 & 88.3 & 96.2 \\
\hline Yes & 5.4 & 0.004 & 4.5 & 6.3 & 7.8 & 0.019 & 3.8 & 11.7 \\
\hline
\end{tabular}

$S E$ standard error

$* p<0.05$

\section{Gradient Effect of BMI on 12-Month MDD \\ (Unadjusted Model)}

As Table 5 shows, level of BMI was positively associated with odds of 12-month MDD among Black Caribbean and African American Women. BMI level was, however, negatively associated with odds of 12-month MDD among Black Caribbean and African American men. From the above four ethnicitygender groups, the gradient effect of BMI level reached significance only among African American men $(\mathrm{OR}=0.71$, $95 \% \mathrm{CI}=0.51-0.99)($ Table 5).

\section{Threshold Effect of BMI on 12-Month MDD (Unadjusted} Model)

When we tested the threshold effect of different BMI cut-offs among Black men, for African Americans, BMI $\geq 30, \mathrm{BMI} \geq 35$, and $\mathrm{BMI} \geq 40 \mathrm{~kg} / \mathrm{m}^{2}$ were all associated with lower odds of 12-month MDD (OR ranged between 0.10 and 0.48); however, only the effect of $\mathrm{BMI} \geq 35 \mathrm{~kg} / \mathrm{m}^{2}$ reached significance level $(\mathrm{OR}=0.10,95 \% \mathrm{CI}=0.01-0.88)$. For Black Caribbean men, BMI $\geq 30 \mathrm{~kg} / \mathrm{m}^{2}$ and $\mathrm{BMI} \geq 40 \mathrm{~kg} / \mathrm{m}^{2}$ were associated with higher odds of developing 12-month MDD, and BMI $\geq 35$ was associated with lower odds of 12-month MDD; none of these associations reached significance level (Table 5).

When we tested the threshold effect of different BMI cutoffs among Black women, for African Americans, BMI $\geq 30$, $\mathrm{BMI} \geq 35$, and $\mathrm{BMI} \geq 40 \mathrm{~kg} / \mathrm{m}^{2}$ were all associated with higher odds of 12-month MDD (OR ranging between 1.14 and 1.44); however, none of these associations reached significance level. For Black Caribbean women, BMI $\geq 30 \mathrm{~kg} / \mathrm{m}^{2}$ and BMI $\geq 35 \mathrm{~kg} / \mathrm{m}^{2}$ were also associated with higher odds of 12-month MDD. For BMI $\geq 40 \mathrm{~kg} / \mathrm{m}^{2}$ among Caribbean Black women, however, this was accompanied with lower odds of developing 12-month $\mathrm{MDD}(\mathrm{OR}=0.05,95 \% \mathrm{CI}=0.00-0.43)$, which was statistically significant $(p=0.03)$ (Table 5).

Table 3 Distribution of major depressive disorder and body mass index (BMI) level among African Americans

\begin{tabular}{|c|c|c|c|c|c|c|c|c|}
\hline \multirow[t]{2}{*}{ Characteristics } & \multicolumn{4}{|l|}{ Men } & \multicolumn{4}{|c|}{ Women } \\
\hline & $\%$ & SE & Lower bound & Upper bound & $\%$ & SE & Lower bound & Upper bound \\
\hline \multicolumn{9}{|l|}{ BMI level } \\
\hline Underweight (BMI <18.5) & 0.9 & 0.003 & 0.5 & 1.7 & 2.3 & 0.004 & 1.4 & 3.1 \\
\hline Healthy weight (BMI 18.5-24.9) & 29.4 & 0.016 & 26.2 & 32.6 & 27.2 & 0.009 & 25.3 & 29.1 \\
\hline Overweight (BMI 25.0-29.9) & 40.4 & 0.013 & 37.7 & 43.1 & 30.1 & 0.011 & 27.9 & 32.4 \\
\hline Obesity class I (BMI 30.0-34.9) & 18.7 & 0.011 & 16.4 & 20.9 & 21.9 & 0.010 & 19.9 & 23.9 \\
\hline Obesity class II (35.0-39.9) & 6.6 & 0.007 & 5.2 & 7.9 & 10.8 & 0.008 & 9.1 & 12.5 \\
\hline Obesity class III (BMI >40) & 4.0 & 0.007 & 2.7 & 5.3 & 7.7 & 0.006 & 6.6 & 8.8 \\
\hline \multicolumn{9}{|l|}{ Depression in past year } \\
\hline No & 96.9 & 0.005 & 95.9 & 97.9 & 92.7 & 0.005 & 91.6 & 93.9 \\
\hline Yes & 3.1 & 0.005 & 2.1 & 4.1 & 7.3 & 0.005 & 6.1 & 8.4 \\
\hline
\end{tabular}


Table 4 Distribution of major depressive disorder and body mass index (BMI) level among Caribbean Blacks

\begin{tabular}{|c|c|c|c|c|c|c|c|c|}
\hline \multirow[t]{2}{*}{ Characteristics } & \multirow[b]{2}{*}{$\begin{array}{l}\% \\
\text { Men }\end{array}$} & \multirow[b]{2}{*}{ SE } & \multicolumn{2}{|l|}{$95 \% \mathrm{CI}$} & \multirow[b]{2}{*}{$\begin{array}{l}\% \\
\text { Women }\end{array}$} & \multirow[b]{2}{*}{ SE } & \multicolumn{2}{|l|}{$95 \% \mathrm{CI}$} \\
\hline & & & Lower bound & Upper bound & & & Lower bound & Upper bound \\
\hline \multicolumn{9}{|l|}{ BMI level } \\
\hline Underweight (BMI <18.5) & 1.3 & 0.006 & 0.1 & 2.6 & 1.6 & 0.006 & 0.3 & 2.9 \\
\hline Healthy weight (BMI 18.5-24.9) & 39.9 & 0.025 & 34.7 & 45.2 & 35.9 & 0.017 & 32.4 & 39.3 \\
\hline Overweight (BMI 25.0-29.9) & 40.1 & 0.037 & 32.5 & 47.6 & 31.6 & 0.020 & 27.4 & 35.7 \\
\hline Obesity class I (BMI 30.0-34.9) & 12.6 & 0.033 & 5.7 & 19.5 & 16.0 & 0.016 & 12.6 & 19.3 \\
\hline Obesity class II (35.0-39.9) & 5.4 & 0.021 & 1.0 & 9.8 & 9.2 & 0.019 & 5.2 & 13.2 \\
\hline Obesity class III (BMI >40) & 0.6 & 0.003 & 0.1 & 1.2 & 5.8 & 0.015 & 2.6 & 9.0 \\
\hline \multicolumn{9}{|l|}{ Depression in past year } \\
\hline No & 89.8 & 0.039 & 81.8 & 97.8 & 94.8 & 0.012 & 92.3 & 97.2 \\
\hline Yes & 10.2 & 0.039 & 2.2 & 18.2 & 5.2 & 0.012 & 2.8 & 7.7 \\
\hline
\end{tabular}

$S E$ standard error, $C I$ confidence interval

The associations between $\mathrm{BMI} \geq 35$ and depression among African American men and the association between BMI $\geq 40 \mathrm{~kg} / \mathrm{m}^{2}$ among Caribbean Black women stayed significant in the adjusted models (Table 6).

When we entered the product of BMI levels and ethnicity as an interaction term to our models, we found a significant interaction between $\mathrm{BMI} \geq 40(\mathrm{OR}=0.16,95 \% \mathrm{CI}=0.026$ $0.97, p=0.048$ ) and ethnicity (change in $\mathrm{OR}=8.84,95 \% \mathrm{CI}=$ 1.31-59.42, $p=0.026$ for African Americans) among women. The same result could not be replicated for men. We could not find an interaction between other BMI thresholds and ethnicity.

\section{Discussion}

Analyzing data from the NSAL, we systematically examined the difference between African Americans and Caribbean Blacks in the direction and magnitude of the association between obesity and major depressive disorder. The main motivation behind our study was the publication by Gavin et al. [16] who documented an interaction between obesity and race on MDD; however, the study combined African Americans and Caribbean Blacks.
Table 5 Unadjusted odds ratios associated with gradient and threshold effects of body mass index (BMI) on 12-month major depressive disorder
Numbers presented in bold represent significant associations

$C I$ confidence interval $* p<0.05$

\begin{tabular}{|c|c|c|c|c|c|c|}
\hline \multirow[t]{2}{*}{ Characteristics } & \multirow[b]{2}{*}{$\begin{array}{l}\text { Odds Ratio } \\
\text { Men }\end{array}$} & \multicolumn{2}{|c|}{$95 \% \mathrm{CI}$} & \multirow[b]{2}{*}{$\begin{array}{l}\text { Odds Ratio } \\
\text { Women }\end{array}$} & \multicolumn{2}{|c|}{$95 \% \mathrm{CI}$} \\
\hline & & $\begin{array}{l}\text { Lower } \\
\text { bound }\end{array}$ & $\begin{array}{l}\text { Upper } \\
\text { bound }\end{array}$ & & $\begin{array}{l}\text { Lower } \\
\text { bound }\end{array}$ & $\begin{array}{l}\text { Upper } \\
\text { bound }\end{array}$ \\
\hline \multicolumn{7}{|l|}{ Gradient effect } \\
\hline African American & $0.71^{*}$ & 0.51 & 0.99 & 1.11 & 0.94 & 1.33 \\
\hline Black Caribbean & 0.76 & 0.25 & 2.36 & 1.22 & 0.89 & 1.67 \\
\hline \multicolumn{7}{|l|}{ Threshold effect } \\
\hline \multicolumn{7}{|l|}{$\mathrm{BMI} \geq 30 \mathrm{~kg} / \mathrm{m}^{2}$} \\
\hline African American & 0.48 & 0.18 & 1.29 & 1.14 & 0.78 & 1.67 \\
\hline Black Caribbean & 1.59 & 0.20 & 12.93 & 1.39 & 0.53 & 3.66 \\
\hline \multicolumn{7}{|l|}{$\mathrm{BMI} \geq 35 \mathrm{~kg} / \mathrm{m}^{2}$} \\
\hline African American & $0.10^{*}$ & 0.01 & 0.88 & 1.42 & 0.93 & 2.18 \\
\hline Black Caribbean & 0.23 & 0.03 & 1.91 & 1.93 & 0.63 & 5.94 \\
\hline \multicolumn{7}{|l|}{$\mathrm{BMI} \geq 40 \mathrm{~kg} / \mathrm{m}^{2}$} \\
\hline African American & 0.27 & 0.03 & 2.28 & 1.44 & 0.76 & 2.73 \\
\hline Black Caribbean & 1.21 & 0.10 & 14.11 & $0.05^{*}$ & 0.01 & 0.44 \\
\hline
\end{tabular}


Table 6 Adjusted odds ratios associated with gradient and threshold effects of body mass index (BMI) on 12-month major depressive disorder

\begin{tabular}{|c|c|c|c|c|c|c|}
\hline \multirow[t]{2}{*}{ Characteristics } & \multicolumn{3}{|l|}{$95 \% \mathrm{CI}$} & \multicolumn{3}{|l|}{$95 \% \mathrm{CI}$} \\
\hline & $\begin{array}{l}\text { Odds ratio } \\
\text { Men }\end{array}$ & Lower bound & Upper bound & $\begin{array}{l}\text { Odds ratio } \\
\text { Women }\end{array}$ & Lower bound & Upper bound \\
\hline \multicolumn{7}{|l|}{ Gradient effect } \\
\hline African American & 0.71 & 0.50 & 1.01 & 1.15 & 0.99 & 1.35 \\
\hline Black Caribbean & 0.70 & 0.32 & 1.54 & 1.08 & 0.81 & 1.44 \\
\hline \multicolumn{7}{|l|}{ Threshold effect } \\
\hline \multicolumn{7}{|l|}{$\mathrm{BMI} \geq 30 \mathrm{~kg} / \mathrm{m}^{2}$} \\
\hline African American & 0.50 & 0.18 & 1.37 & 1.25 & 0.90 & 1.74 \\
\hline Black Caribbean & 1.01 & 0.17 & 6.00 & 1.00 & 0.40 & 2.49 \\
\hline \multicolumn{7}{|l|}{$\mathrm{BMI} \geq 35 \mathrm{~kg} / \mathrm{m}^{2}$} \\
\hline African American & $0.10^{*}$ & 0.01 & 0.87 & $1.50^{*}$ & 1.00 & 2.26 \\
\hline Black Caribbean & 0.23 & 0.03 & 1.74 & 1.25 & 0.39 & 4.03 \\
\hline \multicolumn{7}{|l|}{$\mathrm{BMI} \geq 40 \mathrm{~kg} / \mathrm{m}^{2}$} \\
\hline African American & 0.27 & 0.03 & 2.40 & 1.48 & 0.81 & 2.73 \\
\hline Black Caribbean & 1.30 & 0.09 & 18.54 & $0.03 *$ & 0.00 & 0.43 \\
\hline
\end{tabular}

Age, country region, education, income, marital status, and employment have been controlled

Numbers presented in bold represent significant associations

$C I$ confidence interval

$* p<0.05$

Our findings suggested that the threshold effect of BMI on depression may depend on ethnicity and gender. The gradient effect of BMI level on MDD reached statistical significance only among African American men. Although not statistically significant, the direction of gradient effect of BMI level on depression was reversed among Black men and Black women. Among Black women, higher BMI tended to accompany a higher risk of depression, while for Black men, higher BMI was associated with lower risk of depression. Gender and ethnic differences were also found regarding threshold effects of BMI level on depression. Among African American men, BMI $\geq 35$ was negatively associated with depression, while among Caribbean Black women, BMI $\geq 40$ was associated with lower risk of depression.

A recent meta-analysis reviewed seventeen studies that had enrolled 204,507 participants. After removing two outlier studies, this study concluded an overall significant and positive association between obesity and depression. Although in this study ethnicity did not moderate the association [43], racial differences in the link between obesity and depression have been previously published [17, 44]. In one study for instance, the association between BMI and depressive symptoms was greater among African Americans than Whites [18]. The opposite result was reported by Gavin and coworkers; they found a positive and significant association between obesity and MDD among White women but not among any other gender-ethnic group. Nonsignificant associations between obesity and depression were found among Blacks, Latinos, and Asians [17]. Analysis of the National Comorbidity Survey Replication
(NCS-R) also reported a larger association between obesity and MDD for Whites compared to non-Whites [45].

Our report regarding the inverse association between obesity and 12-month MDD among Black men is in line with the results of a longitudinal study which analyzed data of the National Population Health Survey with 10,545 adults without depression at baseline. In this study, Gariepy and colleagues showed that obesity at baseline reduces the likelihood of a subsequent major depression episode among men but not women [46].

A recent meta-analysis reported an odds ratio of 1.38 (95\% CI, 1.22-1.57) for the effect of abdominal obesity on depression, a relationship which did not vary with gender, age, measurement of depression and abdominal obesity, and study quality [47]. In 2010, a meta-analysis reported a reciprocal link between depression and obesity. The study suggested that the association may be more pronounced among Americans than among Europeans and for depressive disorder than for depressive symptoms. This meta-analysis also did not reveal any moderator for this association [44]. Recently, Gavin and colleges argued that despite the higher prevalence of obesity among racial/ethnic minorities, our understanding of the obesity-depression association among these groups is still limited [17].

In our study, in most gender-ethnic sub-populations, the association between 12-month MDD and BMI level did not reach significance level. This is due to underpowered comparisons, due to breaking the sample into multiple subsamples. Gavin et al. attributed nonsignificant association of depression and MDD among some ethnic groups to the statistical power, which is directly a consequence of a low sample size of minority 
participants and also a relatively low prevalence of depression, especially among men [17]. The same rational may explain our nonsignificant findings.

The literature is limited about the moderating effect of race/ethnicity on the depression-obesity link [48]. While most national surveys include predominantly White samples [17], testing the association between MDD and obesity in racial/ethnic groups other than Whites is less frequently examined. Due to insufficient sample size of racial/ethnic minority groups, researchers limit their report to the pool sample composed of multiple racial groups. However, understanding the pattern of the link between obesity and depression among each ethnic group is imperative to design interventions that address body weight maintenance and reduction strategies among minority groups [17]. We argue that even in the absence of large sample size, the ethnic specific associations are to be reported. Even if the association is not significant, the magnitude of association can still inform us.

Further research is needed on the ethnic differences in the association between obesity and depression. In addition, research on BMI and depression among Blacks should collect data on ethnicity of the participants. Unfortunately, most of the current literature on American Blacks ignores ethnicity and includes a heterogenic group, composed of different ethnic origins. This becomes more problematic when such studies call their samples African Americans instead of Blacks. Another problem is when severity of depression or obesity is conceptualized as moderator for the association between obesity and depression. Such approach may also be seen as an example of collider stratification of $\mathrm{M}$ bias [49-51]. This is a threshold effect, not the moderator [10]. A moderator should always be a third variable, separate from both independent and dependent variables [52].

There are numerous papers which have reported that the impact of obesity on MDD may be nonlinear and appear after a certain level of obesity. For example, a change from underweight status to normal weight or a change from normal weight to overweight status may not necessarily increase the risk of depression of an individual [13, 53-56]. The effect of BMI on MDD may start when passing from overweight to obesity status [44]. There are also studies suggesting a U-shaped association between BMI and mood disorders [12].

Based on this study, ethnicity and gender may modify the association between obesity and depression among Blacks. Thus, the association between gender, ethnicity, obesity and depression should be considered a complex association. Reviewing the result of studies conducted in different parts of the world also confirms this complexity, as the direction of the association between BMI and MDD is very different in the USA compared to East Asia. Although in the USA, most studies have suggested a positive association between obesity and risk of depression, a reverse association has been reported in China [57], Korea [58], and Hong Kong [59]. Interestingly, even in the countries with inverse association, the magnitude of association is stronger among women than men [60-62]. These conflicting results can be explained by the fact that ethnicity shapes life style, life values, and life expectations. In other words, ethnicity may determine an individuals' emotional reaction to obesity, or how depression influences behaviors associated with adiposity. It is still not-known whether obesity causes depression, depression causes obesity, or both can be attributed to common causes such as low socioeconomic status, stressors, lifestyle factors, or molecular and biological factors [63].

The inverse correlation between BMI and depression in Asian countries has been explained by the "Jolly Fat" hypothesis [60]. Based on this theory that was developed by Crisp and McGuiness in 1976, obesity may have a reducing effect on psychoneurosis [64].

Different mechanisms have been used to explain the positive association between depression and obesity. Depression may be present with an increase in food intake and with a decrease in physical activity, which is related to the lack of energy that can result in weight gain. This overlap between presentations of obesity and depression may even result in an over-diagnosis of depression among obese people. Based on this pathway, we can hypothesize that depression may differently be presented among men and women of different ethnic groups. Negative body image and stigma associated with obesity cause depression by lowering self-esteem or increasing psychological distress [65].

As obesity and MDD are both associated with socioeconomic disadvantage [66], it has been argued that the bivariate associations from cross-sectional studies may disappear by controlling the effect of socioeconomic confounders. Our study, however, reported the association of interest after controlling the effect of socioeconomic status.

Biological mechanisms have also been proposed to link obesity to depression; one pathway is an increased hypothalamic-pituitary-adrenal pathway that activates as a result of socioeconomic disadvantage, chronic stress, or excessive alcohol consumption. By this mechanism, a chronically raised circulating cortisol concentration may be responsible for an increased visceral fat depot. Such adiposity may be a direct consequence of increasing adipogenesis or an indirect effect of central factors that increase appetite and food intake [66].

Clinicians should consider the possibility of depression in Black women with excess body weight. Atlantis recommends a full investigation of psychosocial and lifestyle risk factors among people with both obesity and MDD. He believes that effective management of obesity may require approaches to comorbid depression, if present [66].

The current study was limited in several aspects. Crosssectional design of the study limits any inference about the cause and effect. BMI was calculated based on self-reported weight and height. In addition, physical health and psychiatric comorbidities were not included in the analysis. The study could also benefit from measuring variables such as smoking, body image, guilt, eating habits, eating disorders, or physical activity. Mediating effects of these factors should be tested and 
may increase our knowledge about the complex association between ethnicity, gender, depression, and obesity.

To conclude, the pattern of association between obesity and depression among Blacks is not uniform and varies based on ethnicity and gender. Clinical and public health programs that wish to prevent or treat comorbid depression and obesity among Blacks may benefit from tailoring for ethnicity and gender of the target population.

Funding/Support The NSAL is mostly supported by the National Institute of Mental Health, with grant U01-MH57716. Other support came from the Office of Behavioral and Social Science Research at the National Institutes of Health and the University of Michigan. For this analysis, the public data set was downloaded from Interuniversity Consortium for Political and Social Research (ICPSR), Institute for Social Research at the University of Michigan.

\section{References}

1. Ogden CL, Carroll MD, Curtin LR, McDowell MA, Tabak CJ, Flegal KM. Prevalence of overweight and obesity in the United States, 1999-2004. JAMA. 2006;295(13):1549-55.

2. WHO, 2006. http://www.euro.who.int/HEN/Syntheses/short/20040908_1

3. Allison DB, Zanolli R, Narayan KM. The direct health care costs of obesity in the United States. Am J Public Health. 1999;89:1194-9.

4. Druss BG, Rosenheck RA, Sledge WH. Health and disability costs of depressive illness in a major US corporation. Am J Psychiatr. 2000;157:1274-8.

5. Simon GE, Barber C, Birnbaum HG, Frank RG, Greenberg PE, Rose RM, et al. Depression and work productivity: the comparative costs of treatment versus nontreatment. J Occup Environ Med. 2001;43(1):2-9.

6. Adams KF, Schatzkin A, Harris TB, Kipnis V, Mouw T, BallardBarbash R, et al. Overweight, obesity, and mortality in a large prospective cohort of persons 50 to 71 years old. N Engl J Med. 2006;355(8):763-78.

7. Kessler RC, Berglund P, Demler O, Jin R, Koretz D, Merikangas KR, et al. The epidemiology of major depressive disorder: results from the National Comorbidity Survey Replication (NCS-R). J Am Med Assoc. 2003;289(23):3095-105.

8. Friedman MA, Brownell KD. Psychological correlates of obesity: moving to the next generation. Psychol Bull. 1995;117:3-20.

9. Centers for Disease Control and Prevention (CDC). Differences in prevalence of obesity among black, white, and Hispanic adultsUnited States, 2006-2008. MMWR Morb Mortal Wkly Rep. 2009;58(27):740-4.

10. Stunkard AJ, Faith MS, Anderson KC. Depression and obesity. Biol Psychiatry. 2003;54:330-7.

11. Ohayon MM, Hong SC. Prevalence of major depressive disorder in the general population of South Korea. J Psychiatr Res. 2006;40:30-6.

12. Carpenter KM, Hasin DS, Allison DB, Faith MS. Relationships between obesity and DSM-IV major depressive disorder, suicide ideation, and suicide attempts: results from a general population study. Am J Public Health. 2000;90(2):251-7.

13. Onyike CU, Crum RM, Lee HB, Lyketsos CG, Eaton WW. Is obesity associated with major depression? Results from the third national health and nutrition examination survey. Am J Epidemiol. 2003;58:1136- 47.

14. McIntyre RS, Konarski JZ, Wilkins K, Soczynska JK, Kennedy SH. Obesity in bipolar disorder and major depressive disorder: results from a national community health survey on mental health and wellbeing. Can J Psychiatry. 2006;51(5):274-80.
15. Scott KM, Bruffaerts R, Simon GE, Alonso J, Angermeyer M, de Girolamo G, et al. Obesity and mental disorders in the general population: results from the world mental health surveys. Int J Obes (Lond). 2008;32(1):192-200.

16. Gavin AR, Rue T, Takeuchi D. Racial/ethnic differences in the association between obesity and major depressive disorder: findings from the Comprehensive Psychiatric Epidemiology Surveys. Public Health Rep. 2010;125(5):698-708.

17. Gavin AR, Rue T, Takeuchi D. Racial/ethnic differences in the association between obesity and major depressive disorder: findings from the Comprehensive Psychiatric Epidemiology Surveys. Public Health Rep. 2010;125(5):698-708.

18. Sachs-Ericsson N, Burns AB, Gordon KH, Eckel LA, Wonderlich SA, Crosby RD, et al. Body mass index and depressive symptoms in older adults: the moderating roles of race, sex, and socioeconomic status. Am J Geriatr Psychiatr. 2007;15(9):815-25.

19. Andersen JR, Aasprang A, Bergsholm P, Sletteskog N, Våge V, Natvig GK. Anxiety and depression in association with morbid obesity: changes with improved physical health after duodenal switch. Health Qual Life Outcome. 2010;8:52.

20. Fabricatore AN, Wadden TA, Sarwer DB, Faith MS. Health-related quality of life and symptoms of depression in extremely obese persons seeking bariatric surgery. Obes Surg. 2005;15:304-9.

21. Dixon JB, Dixon ME, O'Brien PE. Depression in association with severe obesity: changes with weight loss. Arch Intern Med. 2003;163:2058-65.

22. Jackson JS, Torres M, Caldwell CH, Neighbors HW, Nesse RM, Taylor RJ, et al. The National Survey of American Life: a study of racial, ethnic, and cultural influences on mental disorders and mental health. Int J Methods Psychiatr Res. 2004;13:196-207.

23. Jackson JS, Neighbors HW, Nesse RM, Trierweiler SJ, Torres M. Methodological innovations in the National Survey of American Life. Int J Methods Psychiatr Res. 2004;13:289-98.

24. Heeringa S, Wagner J, Torres M, Duan N, Adams T, Berglund P. Sample designs and sampling methods for the Collaborative Psychiatric Epidemiology Studies (CPES). Int J Methods Psychiatr Res. 2004;13(4):221-39.

25. Taylor RJ, Nguyen AW, Sinkewicz M, Joe S, Chatters LM. Comorbid mood and anxiety disorders, suicidal behavior, and substance abuse among black Caribbeans in the U.S.A. Journal of African American Studies. J Afr Am Stud. 2013;17(4):409-25.

26. Taylor RJ, Chatters LM, Nguyen AW. Religious participation and DSM IV major depressive disorder among black Caribbeans in the United States. J Immigr Minor Health. 2013;15(5):903-9. doi:10. 1007/s10903-012-9693-4.

27. Becares L, Nazroo J, Jackson J, Heuvelman H. Ethnic density effects on health and experienced racism among Caribbean people in the US and England: a cross-national comparison. Soc Sci Med. 2012;75(12):2107-15.

28. Taylor RJ, Chatters LM, Mattis JS, Joe S. Religious involvement among Caribbean blacks residing in the United States. Rev Relig Res. 2010;52(2):125-45.

29. Taylor RJ, Woodward AT, Chatters LM, Mattis JS, Jackson JS. Seeking help from clergy among black Caribbeans in the United States. J Race Soc Probl. 2011;3(4):241-51.

30. Kessler RC, Ustun TB. The World Mental Health (WMH) survey initiative version of the World Health Organization (WHO) Composite International Diagnostic Interview (CIDI). Int J Methods Psychiatr Res. 2004;13:93-121.

31. Robins LN, Wing J, Wittchen HU, Helzer JE, Babor TF, Burke J, et al. The Composite International Diagnostic Interview. An epidemiologic instrument suitable for use in conjunction with different diagnostic systems and in different cultures. Arch Gen Psychiatry. 1988;45:1069-77.

32. Wittchen HU. Reliability and validity studies of the WHOComposite International Diagnostic Interview (CIDI): a critical review. J Psychiatr Res. 1994;28:57-84. 
33. Kessler RC, Wittchen H-U, Abelson JM, McGonagle KA, Schwarz $\mathrm{N}$, Kendler KS, et al. Methodological studies of the Composite International Diagnostic Interview (CIDI) in the US National Comorbidity Survey. Int J Methods Psychiatr Res. 1998;7:33-55.

34. Kessler RC, Calabrese JR, Farley PA, Gruber MJ, Jewell MA, Katon $\mathrm{W}$, et al. Composite International Diagnostic Interview screening scales for DSM-IV anxiety and mood disorders. Psychol Med. 2013;43(8):1625-37. doi:10.1017/S0033291712002334.

35. Williams DR, Haile R, González HM, Neighbors H, Baser R, Jackson JS. The mental health of Black Caribbean immigrants: results from the National Survey of American Life. Am J Public Health. 2007;97(1):52-9.

36. Jackson JS, Neighbors HW, Torres M, Martin LA, Williams DR, Baser R. Use of mental health services and subjective satisfaction with treatment among Black Caribbean immigrants: results from the National Survey of American Life. Am J Public Health. 2007;97(1): 60-7.

37. Neighbors HW, Caldwell C, Williams DR, Nesse R, Taylor RJ, Bullard KM, et al. Race, ethnicity, and the use of services for mental disorders: results from the National Survey of American Life. Arch Gen Psychiatry. 2007;64(4):485-94.

38. Woodward AT, Taylor RJ, Abelson JM, Matusko N. Major depressive disorder among older African Americans, Caribbean blacks, and non-Hispanic whites: secondary analysis of the National Survey of American Life. Depress Anxiety. 2013;30(6):589-97. doi:10.1002/ da.22041. Epub 2013 Jan 14.

39. Assari S, Lankarani MM, Moazen B. Religious beliefs may reduce the negative effect of psychiatric disorders on age of onset of suicidal ideation among Blacks in the United States. Int J Prev Med. 2012;3(5):358-64.

40. Assari S, Moghani Lankarani M, Moghani Lankarani R. Ethnicity modifies the effects of anxiety and drug use on suicidal ideation among Black adults in the United States. Int J Prev Med. 2013;4(11):1151.

41. Simon GE, Von Korff M, Saunders K, Miglioretti DL, Crane PK, van Belle G, et al. Association between obesity and psychiatric disorders in the US adult population. Arch Gen Psychiatry. 2006;63(7):824 30.

42. Taylor AW, Dal Grande E, Gill TK, Chittleborough CR, Wilson DH, Adams RJ, et al. How valid are self-reported height and weight? A comparison between CATI self-report and clinic measurements using a large cohort study. Aust N Z J Public Health. 2006;30(3):238-46.

43. de Wit L, Luppino F, van Straten A, Penninx B, Zitman F, Cuijpers P. Depression and obesity: a meta-analysis of community-based studies. Psychiatry Res. 2010;178(2):230-5.

44. Luppino FS, de Wit LM, Bouvy PF, Stijnen T, Cuijpers P, Penninx BW, et al. Overweight, obesity, and depression: a systematic review and meta-analysis of longitudinal studies. Arch Gen Psychiatry. 2010;67(3):220-9.

45. Simon GE, Von Korff M, Saunders K, Miglioretti DL, Crane PK, van Belle G, et al. Association between obesity and psychiatric disorders in the US adult population. Arch Gen Psychiatry. 2006;63:824-30.

46. Gariepy G, Wang J, Lesage AD, Schmitz N. The longitudinal association from obesity to depression: results from the 12-year National Population Health Survey. Obesity (Silver Spring). 2010;18(5): 1033-8.

47. Xu Q, Anderson DJ, Lurie-Beck J. Karen The relationship between abdominal obesity and depression in the general population: a systematic review and meta-analysis. Obes Res Clin Pract. 2011;5(4): e267-78.
48. Mizell CA. Life course influences on African American men's depression: adolescent parental composition, self-concept, and adult earnings. J Black Stud. 1999;29:467-90.

49. Cole SR, Platt RW, Schisterman EF, Chu H, Westreich D, Richardson $\mathrm{D}$, et al. Illustrating bias due to conditioning on a collider. Int $\mathrm{J}$ Epidemiol. 2010;39(2):417-20. doi:10.1093/ije/dyp334. Epub 2009 Nov 19.

50. Greenland S. Quantifying biases in causal models: classical confounding vs collider-stratification bias. Epidemiology. 2003;14(3):300-6.

51. Liu W, Brookhart MA, Schneeweiss S, Mi X, Setoguchi S. Implications of $\mathrm{M}$ bias in epidemiologic studies: a simulation study. Am J Epidemiol. 2012;176(10):938-48. doi:10.1093/aje/kws165. Epub 2012 Oct 25.

52. Baron RM, Kenny DA. The moderator-mediator variable distinction in social psychological research: conceptual, strategic, and statistical considerations. J Pers Soc Psychol. 1986;51(6):1173-82.

53. John U, Meyer C, Rumpf HJ, Hapke U. Relationships of psychiatric disorders with overweight and obesity in an adult general population. Obes Res. 2005;13:101-9.

54. Petry NM, Barry D, Pietrzak RH, Wagner JA. Overweight and obesity are associated with psychiatric disorders: results from the National Epidemiologic Survey on Alcohol and Related Conditions. Psychosom Med. 2008;70(3):288-97.

55. Barry D, Pietrzak RH, Petry NM. Gender differences in associations between body mass index and DSM-IV mood and anxiety disorders: results from the National Epidemiologic Survey on Alcohol and Related Conditions. Ann Epidemiol. 2008;18(6):458-66.

56. Jorm AF, Korten AE, Christensen H, Jacomb PA, Rodgers B, Parslow RA. Association of obesity with anxiety, depression and emotional well-being: a community survey. Aust N Z J Public Health. 2003;27(4):434-40.

57. Ho RC, Niti M, Kua EH, Ng TP. Body mass index, waist circumference, waist-hip ratio and depressive symptoms in Chinese elderly: a population-based study. Int J Geriatr Psychiatr. 2008;23(4):401-8.

58. Kim E, Song JH, Hwang JY, Ahn K, Kim J, Koh YH, et al. Obesity and depressive symptoms in elderly Koreans: evidence for the "Jolly Fat" hypothesis from the Ansan Geriatric (AGE) Study. Arch Gerontol Geriatr. 2010;51(2):231-4.

59. Kuo SY, Lin KM, Chen CY, Chuang YL, Chen WJ. Depression trajectories and obesity among the elderly in Taiwan. Psychol Med. 2011;41(8):1665-76.

60. Kim E, Song JH, Hwang JY, Ahn K, Kim J, Koh YH, et al. Obesity and depressive symptoms in elderly Koreans: evidence for the "Jolly Fat" hypothesis from the Ansan Geriatric (AGE) Study. Arch Gerontol Geriatr. 2010;51(2):231-4.

61. Li ZB, Ho SY, Chan WM, Ho KS, Li MP, Leung GM, et al. Obesity and depressive symptoms in Chinese elderly. Int J Geriatr Psychiatr. 2004;19(1):68-74.

62. Kim JY, Chang HM, Cho JJ, Yoo SH, Kim SY. Relationship between obesity and depression in the Korean working population. J Korean Med Sci. 2010;25(11):1560-7.

63. Beydoun MA, Wang Y. Pathways linking socioeconomic status to obesity through depression and lifestyle factors among young US adults. J Affect Disord. 2010;123(1-3):52-63.

64. Crisp AH, McGuiness B. Jolly fat: relation between obesity and psychoneurosis in general population. Br Med J. 1975;1:7-9.

65. Ross CE. Overweight and depression. J Health Soc Behav. 1994;35: 63-79.

66. Atlantis E, Goldney RD, Wittert GA. Obesity and depression or anxiety. BMJ. 2009;339:b3868. 